\title{
Peran Konformitas Teman Sebaya dan Kenyamanan Pelayanan Terhadap Perilaku Konsumtif Melalui Shopee pada Mahasiswa Fakultas Psikologi Unissula
}

\section{The Role Peer Conformity and Service Convenience Towards Consumptive Behavior Through Shopee Among Students in Faculty of Psychology Unissula}

\author{
Rizqi Ananda Putri ${ }^{1 *}$, Diany Ufieta Syafitri ${ }^{2}$ \\ 1,2 Faculty of Psychology Sultan Agung Islamic University, Semarang
}

Received May 24, 2021| Accepted September 17, 2021| Published Desember 15, 2021

\begin{abstract}
Abstrak: Perkembangan teknologi yang pesat telah memunculkan banyak platform berbelanja online di Indonesia. Hal ini pun disambut oleh masyarakat Indonesia dengan daya beli yang tinggi pula. Di sisi lain, hal ini juga mengakibatkan permasalahan perilaku konsumtif pada kalangan mahasiswa terutama melalui platform Shopee karena dinilai memiliki pelayanan nyaman dan mudah. Selain itu, belanja online juga dipengaruhi oleh konformitas dengan teman sebaya. Penelitian ini bertujuan mengetahui peran konformitas teman sebaya dan kenyamanan pelayanan terhadap perilaku belanja konsumtif online melalui Shopee pada mahasiswa Fakultas Psikologi UNISSULA. Penelitian dilakukan pada 270 mahasiswa yang ditentukan melalui teknik cluster random sampling. Hasil analisis menggunakan regresi berganda menunjukkan $R$ 0,779, F 206,697, p 0,000 $(p<0,01)$, sumbangan efektif $60,8 \%$ yang berarti bahwa konformitas teman sebaya dan kenyamanan pelayanan berkontribusi secara signifikan terhadap perilaku konsumtif.
\end{abstract}

Kata Kunci: perilaku konsumtif; konformitas teman sebaya; kenyamanan pelayanan

\begin{abstract}
Rapid technological developments increased the use of many online shopping platforms in Indonesia. This is also welcomed by the people of Indonesia with high purchasing power as well. On the other hand, this has also resulted in the problem of consumptive behavior among university students, especially through the Shopee platform because it is considered to have a convenient and easy services. In addition, online shopping is also influenced by conformity with peers. This study aimed to determine the role of peer conformity and service convenience on online consumptive shopping behavior through Shopee on Unissula Psychology Faculty students. The study was conducted on 270 students who were determined through cluster random sampling technique. The results of the analysis using multiple regression showed $R 0.779, F$ 206.697, $p 0.000$ ( $p<0.01$ ), with an effective contribution of $60.8 \%$ which means that peer conformity and service convenience contribute significantly to consumptive behavior.
\end{abstract}

Keywords: consumptive behavior; peer conformity; service convenience

\footnotetext{
1* Corresponding Author: Diany Ufieta Syafitri, email: dianysyafitri@unissula.ac.id, Faculty of Psychology Unissula, Jl. Kaligawe Raya km 4, Genuk, Semarang, Indonesia.
} 


\section{Pendahuluan}

Perkembangan teknologi memberikan kemudahan dalam kegiatan jual beli secara digital. Berdasarkan data tahun 2006-2016 yang telah dipublikasikan oleh BPS (Badan Pusat Statistik) terdapat jumlah penjual online shopping mengalami peningkatan hingga $17 \%$ yang berjumlah sekitar 26,2 juta penduduk di Indonesia (Septian, 2016). Terdapat beberapa platform online shopping yang populer di kalangan masyarakat Indonesia seperti Shopee, Tokopedia, Bukalapak, dan lain sebagainya. Menurut data dari databoks rata-rata pengunjung aplikasi online shopping tertinggi adalah Shopee sebanyak 93,4 juta, diikuti Tokopedia sebanyak 86,1 juta, Bukalapak sebanyak 35,3 juta, Lazada sebanyak 22 juta, dan Blibli sebanyak 18,3 juta. Hal ini menunjukkan bahwa Shopee berhasil menguasai pasaran atau peringkat pertama aplikasi belanja online shopping (Dwi, 2020).

Adanya kemudahan dalam melakukan belanja online melalui platform berbelanja di atas tampaknya direspon dengan baik oleh masyarakat Indonesia. Hasil survei yang dilakukan oleh lembaga We Are Social menunjukkan bahwa Indonesia menjadi negara tertinggi yang melakukan belanja online, bahkan $87 \%$ responden Indonesia menyampaikan bahwa setidaknya mereka membeli 1 barang dalam 1 bulan terakhir (CNN Indonesia, 2021). Terlebih dalam kondisi pandemi, pengeluaran untuk belanja online dilaporkan meningkat terutama untuk hobi yaitu sebesar 14,626,4\% (Astutik, 2021).

Mahasiswa merupakan segmen yang memiliki minat tinggi dalam online shopping melalui Shopee karena menyediakan fitur promosi, banyaknya promo yang ditawarkan oleh toko, adanya voucher yang disediakan, produk pilihan toko dan fitur goyang Shopee dan Shopee live (Shopee, 2019; Henry, 2019). Hampir setiap hari mahasiswa selalu melakukan kegiatan pembelian barang untuk kepuasan pada masa hidupnya. Pembelian yang paling sering dilakukan oleh mahasiswa ialah fashion dan pembelian tiket secara online karena dirasa lebih mudah (Veritrans, 2012). Hal ini juga diperkuat oleh hasil survei awal yang dilakukan pada 38 mahasiswa Fakultas Psikologi di Universitas Islam Sultan Agung melalui survei daring terkait kegiatan belanja online dan mendapatkan hasil bahwa Shopee merupakan platform favorit mereka karena mudah diakses, gratis ongkos kirim (ongkir), dan praktis. Selain itu alasan yang memutuskan konsumen untuk membeli barang pada platform tersebut karena platform yang terpercaya, banyak gratis ongkir, voucher, kemudahan aplikasi di akses dan kemudahan transaksi, harga yang terjangkau, dan mudahnya mendapatkan informasi tentang produk yang hendak dibeli.

Mudahnya akses terhadap belanja online telah memunculkan masalah perilaku konsumtif, yaitu perilaku konsumen yang cenderung melakukan konsumsi secara berlebihan, di mana pembelian produk dilakukan karena keinginan bukan kebutuhan (Ancok, 1995). Perilaku konsumtif juga merupakan adanya aktivitas untuk membeli produk tanpa adanya pertimbangan yang matang dan tidak didasari oleh faktor kebutuhan serta tanpa adanya pertimbangan pemikiran yang rasional (Sumartono, 2002;Wahyudi, 2013). Hasil survei yang dilakukan aplikasi Snapcart pada tahun 2018 menunjukkan bahwa pengguna terbanyak platform belanja online adalah usia 25-34 tahun (50\%) 
diikuti oleh usia 15-24 tahun (31\%) dengan pembelanjaan tertinggi pada pakaian, aksesori, sepatu, tas, dan perawatan kulit (Sugianto, 2018). Seperti dijelaskan sebelumnya, pada penelitian We Are Social, responden Indonesia juga melaporkan setidaknya membeli satu barang dalam kurun satu bulan terakhir (CNN Indonesia, 2021). Lebih lanjut, nilai transasksi e-commerce di Indonesia terus mengalami peningkatan, di mana pada tahun 2020 sebesar Rp 253 Triliun menjadi lebih dari 300 Triliun pada tahun 2021 (Uly, 2021). Shopee, sebagai platform e-commerce yang paling banyak digunakan mencapai nilai transaksi bruto sebesar US\$14,2 miliar dengan pangsa pasar $37 \%$ pada tahun 2020 (Burhan, 2021).

Adanya permasalahan perilaku konsumtif juga ditunjukkan oleh hasil wawancara awal terhadap beberapa mahasiswa Fakultas Psikologi Unissula, yaitu sebagai berikut.

"Iya, kalau lagi bosen terkadang aku suka buka shopee terus tiba-tiba membeli barang hanya karena kainginan hasrat, shopee lebih memudahkan dalam transaksi dan kemudahan mencari produk yang aku inginkan sehingga penampilan saya tidak ketinggalan oleh lingkungan saya" (NIM, Perempuan, Jurusan Psikologi, Usia 21 Tahun, Angkatan 2017, Universitas Islam Sultan Agung)

"Iya, karena misalnya aku lagi stress suka berbelanja hal-hal yang tidak terlalu penting dan juga biasanya saya berbelanja karena ingin mengikuti tren teman disekitar saya biasanya saya suka berbelanja di shopee karena lebih memudahkan penggunaan dan terjamin kualitas serta banyak ongir" (TIFP, Perempuan, Jurusan Psikologi, Usia 20 tahun, Angkatan 2017, Universitas Islam Sultan Agung)

Dari hasil wawancara awal tersebut dapat dilihat bahwa mahasiswa memiliki kecenderungan untuk membeli barang tanpa mempertimbangkan kebermanfaatan jangka panjang. Aspek-aspek perilaku konsumtif terdiri dari tiga (Sumartono, 2002) yaitu diantaranya: Pertama, pembelian impulsif, menunjukan bahwa konsumen membeli suatu barang hanya di karena untuk memenuhi hasrat keinginan sesaat, yang dilakukan oleh individu tanpa adanya pertimbangan yang logis, tidak memikirkan akibat dari perbuatan pembelian konsumtif dan memiliki sifat emosional. Kedua, pemborosan, merupakan perilaku konsumtif yang menghambur-hamburkan uang yang cukup banyak hanya untuk kepuasan membeli barang yang tidak di kebutuhan atau tidak jelas. Ketiga, pembelian secara tidak rasional, Perilaku konsumen membeli suatu barang hanya untuk kesenangan, memuaskan hasrat dan mengikuti trendy.

Hasil penelitian lebih lanjut menunjukkan bahwa terdapat berbagai faktor yang mempengaruhi perilaku konsumtif yaitu faktor kebudayaan seperti kelas sosial, dan subbudaya, faktor sosial seperti keluarga, status dan peran, faktor pribadi seperti tahapan dalam hidup dan umur, dan faktor psikologi seperti kepercayaan, motivasi dan sikap (Setiadi, 2013). Dalam penelitian ini, ditemukan bahwa salah satu hal yang mempengaruhi perilaku konsumtif para mahasiswa adalah adanya konformitas dengan teman sebaya, di mana beberap mahasiswa yang diwawancarai menunjukkan adanya pengaruh dari teman untuk melakukan pembelian di Shopee. Hasil-hasil penelitian sebelumnya juga menunjukkan adanya pengaruh konformitas dalam perilaku konsumtif. Penelitian terkait hubungan antara konformitas dan perilaku konsumtif pada mahasiswa dan siswa SMA yang dilakukan Fitriyani dkk., (2013), Idham dan Mujiasih, (2017), dan Khafida dan Nrh (2020) 
menunjukkan bahwa terdapat hubungan yang signifikan antara konformitas teman sebaya dengan perilaku konsumtif, di mana semakin tinggi konformitas maka akan semakin tinggi pula perilaku konsumtif.

Konformitas didefinisikan sebagai adanya usaha untuk senantiasa dapat beradaptasi dengan teman sebaya dengan perilaku yang sama karena adanya tekanan yang jelas berasal dari teman sebaya agar dapat mendapatkan target tertentu (Azizah \& Listiara, 2017). Lebih lanjut, konformitas merupakan terdapatnya perubahan perilaku atau kepercayaan untuk dapat mencapai norma yang diharapkan oleh kelompok yang dapat mengakibatkan suatu tekanan kelompok yang nyata (Murtiadi, Danarjati, 2015). Konformitas juga dapat diartikan adanya perubahan perilaku atau kepercayaan individu pada seseorang dengan hasil tekanan satu kelompok yang jelas atau bukan hanya berupa bayangan (Myers, 2012).

Terdapat tiga aspek konformitas menurut pendapat (Sears, 1991) diantaranya adalah : Pertama, kekompakan, adanya perasaan yang dimiliki pada seseorang akan menjadikan acuan individu akan tetap bertahan dan ingin tetap bertahan pada kelompok. Kedua, kesepakatan, adanya prinsip kelompok yang akan menjadi acuan tekanan yang kuat oleh kelompok, dengan begitu kelompok dapat menyesuaikan pendapat di dalam kelompok. Ketiga, ketaatan, adanya tuntutan pada kelompok yang menjadikan remaja rela untuk melakukan tindakan walaupun individu tidak menginginkan tindakan tersebut.

Selain konformitas, faktor lain yang dianggap berkontribusi dalam perilaku konsumtif dalam berbelanja online adalah kenyamanan layanan. Hal ini juga dapat dilihat dari hasil survei dan wawancara awal yang menunjukkan bahwa Shopee memberikan layanan yang memudahkan konsumen untuk melakukan transaksi, mencari barang, gratis ongkos kirim, dan praktis. Penelitian menunjukkan bahwa kenyamanan layanan online merupakan faktor terpenting untuk dapat mempengaruhi faktor keputusan pembelian konsumen secara online (Jiang et al., 2013). Lebih lanjut, kenyamanan layanan ialah dapat memberi efektivitas dan kenyamanan waktu (Berry et al., 2002), di mana dengan layanan yang nyaman konsumen dapat menghemat biaya, waktu dan tenaga (Berry et al., 2002;Kaura, 2013). Konsumen akan merasakan nyaman dan bahagia pada suatu platform belanja memungkinkan konsumen melakukan belanja secara online kembali (Chiang $\&$ Dholakia, 2003).

Hasil-hasil penelitian terkait kenyamanan layanan dalam platform berbelanja online dan pengaruhnya terhadap kepuasan konsumen dan loyalitas pelanggan menunjukkan bahwa adanya hubungan yang positif antara kenyamanan layanan dengan kenyamanan akses ke platform, kenyamanan mencari informasi produk, kenyamanan transaksi, kenyamanan keputusan dan kenyamanan setelah pembelian dengan kepuasaan konsumen terdapat hasil yang berdampak untuk mempengaruhi keputusan pembelian dan semakin tingginya kenyamanan pelayanan maka dengan begitu tinggi pula loyalitas pelanggan. Kenyamanan pelayanan mendapatkan hasil sebesar $24,50 \%$ dari sumbangan terhadap loyalitas pelanggan (Aridinta \& Widijoko, 2019; Sanjaya dkk., 2018).

Kenyamanan layanan atau service convenience adalah konsep pelayanan yang dapat memberikan kenyamanan dengan memberikan kemudahan akses saat berbelanja dan kemudahan transaksi (Cahyanti, 2018). Lebih lanjut, kenyamanan merupakan adanya efektivitas dan efisiensi 
waktu serta usaha dari konsumen agar dapat membeli suatu barang (Duarte et al., 2018). Kenyamanan merupakan hal yang perlu diperhatikan dalam hal berbisnis atau dalam bidang pemasaran, seperti kemudahan akses, kemudahan transaksi dan kemudahan memilih ekspedisi pengiriman barang (Aridinta \& Widijoko, 2019).

Menurut Berry dkk., (2002) terdapat lima aspek kenyamanan layanan yaitu pertama, kenyamanan keputusan (decision convenience), adanya tindakan dari konsumen tentang usaha dan waktu yang telah dilakukan oleh konsumen untuk mendapatkan pembelian layanan atau keputusan pembelian. Kedua, kenyamanan akses (access convenience), adanya tindakan dari konsumen tentang suatu upaya dan waktu yang telah dilakukan oleh konsumen untuk mendapatkan layanan tersebut. Ketiga, kemudahan transaksi (transaction convenience), adanya tindakan dari konsumen tentang suatu usaha dan waktu yang telah dilakukan konsumen untuk dapat melakukan transaksi tersebut. Keempat, kenyamanan manfaat (benefit convenience), adanya tindakan yang berasal dari konsumen tentang upaya dan waktu yang telah dilakukan konsumen agar dapat memanfaatkan inti dari layanan. Kelima, Kenyamanan pasca-manfaat (postbenefit convenience), adanya tindakan dari konsumen tentang upaya dan waktu yang telah dilakukan oleh konsumen untuk dapat berkomunikasi dengan pemasar yang menyediakan layanan setelah tahapan manfaat layanan tersebut.

Berdasarkan paparan di atas, maka penelitian ini bertujuan untuk menjelaskan hubungan antara konformitas dan kenyamanan layanan terhadap perilaku konsumtif melalui Shopee pada mahasiswa.

\section{Metode}

\section{Subjek Penelitian}

Populasi pada penelitian ini yaitu mahasiswa Fakultas Psikologi Universitas Islam Sultan Agung Semarang yang berjumlah sebanyak 631. Sampel pada penelitian ini sebanyak 270 subjek yang diambil melalui cluster random sampling, di mana dilakukan randomisasi berdasarkan kelas di setiap angkatan aktif (kelas A, B, C, dan D untuk angkatan 2020 dan kelas A, B, C untuk angkatan 2017-2019).

Tabel 1.

Jumlah mahasiswa aktif Fakultas Psikologi

\begin{tabular}{ccc}
\hline No & Angkatan & Jumlah Mahasiswa Aktif \\
\hline 1 & 2017 & 123 \\
2 & 2018 & 120 \\
3 & 2019 & 163 \\
4 & 2020 & 225 \\
\hline
\end{tabular}




\section{Alat Ukur}

Alat ukur yang digunakan dalam penelitian merupakan tiga buah skala, yaitu sebagai berikut. Pertama, skala perilaku konsumtif. Skala perilaku konsumtif untuk penelitian ini menggunakan skala perilaku konsumtif yang disusun oleh Mustofa (2019) yang sudah pernah diujikan coba pada anggota club motor dengan koefisiensi reliabilitas Alpha Cronbach 0,875 dengan jumlah aitem 30. Skala ini memiliki empat pilihan jawaban dengan skor 1-4, di mana 1 sangat tidak sesuai dan 4 sangat sesuai. Skala ini kemudian diuji coba lagi oleh peneliti pada subjek mahasiswa Fakultas Psikologi Unissula sejumlah 152 yang terdiri dari 126 perempuan dan 26 laki laki, dengan hasil koefisien reliabilitas Alpha Cronbach 0,968 di mana terdapat satu aitem yang gugur karena memiliki daya diskriminasi di bawah 0,3 sehingga tersisa 29 aitem.

Kedua, skala konformitas teman sebaya. Skala konformitas teman sebaya pada penelitian ini menggunakan yang disusun oleh Priwidianti (2019) yang telah diujicobakan pada 179 siswa SMK dengan koefisiensi reliabilitas Alpha 0,984 dengan jumlah aitem 42. Skala ini memiliki empat pilihan jawaban dengan skor 1-4, di mana 1 sangat tidak sesuai dan 4 sangat sesuai. Skala ini kemudian diuji coba lagi oleh peneliti pada subjek mahasiswa Fakultas Psikologi Unissula sejumlah 152 yang terdiri dari 126 perempuan dan 26 laki laki dengan hasil koefisien reliabilitas Alpha Cronbach 0,916 di mana terdapat 17 aitem yang gugur karena memiliki daya diskriminasi di bawah 0,3 sehingga tersisa 25 aitem.

Ketiga, skala kenyamanan pelayanan. Skala kenyamanan pelayanan disusun sendiri oleh peneliti berdasarkan aspek yang dikemukakan oleh Berry, dkk., (2002) yaitu kenyamanan keputusan, kenyamanan akses, kenyamanan transaksi, kenyamanan manfaat, dan kenyamanan. Skala ini memiliki 40 aitem dengan empat pilihan jawaban dengan skor 1-4, di mana 1 sangat tidak sesuai dan 4 sangat sesuai. Skala ini kemudian diuji coba oleh peneliti pada subjek mahasiswa Fakultas Psikologi Unissula sejumlah 152 yang terdiri dari 126 perempuan dan 26 laki laki dengan hasil koefisien reliabilitas Alpha Cronbach 0,874 di mana terdapat 11 aitem yang gugur karena memiliki daya diskriminasi di bawah 0,3 sehingga tersisa 29 aitem.

\section{Prosedur Penelitian}

Prosedur penelitian ini adalah peneliti menyebarkan tautan kuesioner online yang dibuat melalui google forms pada group chat di Whatsapp kelas setiap angkatan yang terpilih menjadi kelas untuk pengambilan data (kelas ditentukan melalui undian).

\section{Hasil}

Jumlah subjek dalam penelitian ini adalah 270 mahasiswa terdiri dari 220 jawaban perempuan dan 50 jawaban laki-laki yang termasuk 62 jawaban mahasiswa angkatan 2017, 52 jawaban mahasiswa angkatan 2018, 55 jawaban mahasiswa angkatan 2019 dan 101 jawaban mahasiswa angkatan 2020. Berikut ini rincian dalam penelitian ini. 
Tabel 2.

Data Demografi Subjek

\begin{tabular}{|c|c|c|c|c|}
\hline No & Karakteristik & Frekuensi & Presentasi & Total \\
\hline \multirow[t]{5}{*}{1.} & Angkatan & & & 270 \\
\hline & a) 2017 & 62 & $22,2 \%$ & \\
\hline & b) 2018 & 52 & $19,2 \%$ & \\
\hline & c) 2019 & 55 & $20,3 \%$ & \\
\hline & d) 2020 & 101 & $39,3 \%$ & \\
\hline \multirow[t]{5}{*}{2.} & Kelas & & & 270 \\
\hline & a) $\mathrm{A}$ & 54 & $19,3 \%$ & \\
\hline & b) $\mathrm{B}$ & 84 & $31,00 \%$ & \\
\hline & c) $\mathrm{C}$ & 87 & $32,1 \%$ & \\
\hline & d) $\mathrm{D}$ & 45 & $16,6 \%$ & \\
\hline \multirow[t]{3}{*}{3.} & Jenis Kelamin & & & 270 \\
\hline & a) Laki-laki & 50 & $18,5 \%$ & \\
\hline & b) Perempuan & 220 & $80,5 \%$ & \\
\hline \multirow[t]{9}{*}{4.} & Usia & & & 270 \\
\hline & a) 17 tahun & 6 & $2,2 \%$ & \\
\hline & b) 18 tahun & 53 & $19,7 \%$ & \\
\hline & c) 19 tahun & 71 & $26,7 \%$ & \\
\hline & d) 20 tahun & 57 & $21,00 \%$ & \\
\hline & e) 21 tahun & 59 & $21,8 \%$ & \\
\hline & f) 22 tahun & 20 & $7,40 \%$ & \\
\hline & g) 23 tahun & 2 & $0,8 \%$ & \\
\hline & h) 26 tahun & 2 & $0,8 \%$ & \\
\hline
\end{tabular}

Sebelum dilakukan uji hipotesis sebelumnya dilakukan uji asumsi normalitas dan linearitas sebagai berikut.

\section{Uji Asumsi}

\section{Uji Normalitas}

Uji normailtas dilakukan melalui One-Sample Kolmogorov Smirnov Z menunjukkan hasil berikut.

Tabel 2.

Hasil Uji Normalitas

\begin{tabular}{lllllll}
\hline \multicolumn{1}{c}{ Variabel } & Mean & Std Deviasi & KS-Z & Sig & $P$. & Keterangan \\
\hline $\begin{array}{l}\text { Perilaku Konsumtif } \\
\begin{array}{l}\text { Konformitas Teman } \\
\text { Sebaya }\end{array}\end{array}$ & 70,64 & 16,961 & 0,656 & 0,782 & $>0,05$ & Normal \\
$\begin{array}{l}\text { Kenyamanan } \\
\text { Pelayanan }\end{array}$ & 91,33 & 13,459 & 0,668 & 0,764 & $>0,05$ & Normal \\
\hline
\end{tabular}

Psikoislamika: Jurnal Psikologi dan Psikologi Islam 


\section{Uji Multikolinieritas}

Uji multikolinieritas pada penelitian ini didapatkan hasil skor tolerance sebesar 0,855 yang dapat diartikan lebih dari 0,1 dan pada skor VIF mendapatkan hasil sebesar 1,170 yang dapat diartikan lebih kecil dari 10 . Oleh karena itu dapat dikatakan bahwa tidak ada hubungan multikolinieritas dengan variabel bebas.

\section{Uji Hipotesis}

Hipotesis pertama, hasil analisis regresi berganda untuk mengetahui adanya peran konformitas teman sebaya dan kenyamanan pelayanan dengan perilaku konsumtif menunjukkan $R$ 0,779 dan $F$ 206,697, $p$ 0,000 ( $p<0,01$ ) yang berarti hipotesis diterima, di mana konformitas teman sebaya dan kenyamanan pelayanan mampu memprediksi secara sangat signifikan perilaku konsumtif. Lebih lanjut, koefisien prediktor konformitas teman sebaya sebesar 0,876 dan koefisien prediktor kenyamanan pelayanan sebesar 0,325 dengan skor konstan sebesar $-18,719$. Persamaan garis regresinya adalah $Y=0,876 X_{1}+0,325 X_{2}+-18,719$. Sumbangan efektif pada konformitas teman sebaya dan kenyamanan pelayanan dengan perilaku konsumtif secara keseluruhan koefisien determinasi mendapatkan 60,8\%. Hipotesis kedua, pada hipotesis kedua ini menggunakan uji korelasi parsial, di mana hasilnya menunjukkan konformitas teman sebaya dengan perilaku konsumtif memiliki $r_{x 1 y} 0,716, p 0,000(p<0,05)$ yang berarti hipotesis diterima. Hipotesis ketiga, melalui uji korelasi parsial antara kenyamanan pelayanan dengan perilaku konsumtif diperoleh $r_{x l y}$ $0,252, p 0,000(p<0,05)$ yang berarti hipotesis diterima.

\section{Diskusi}

Penelitian ini dilakukan agar dapat mengetahui apakah ada peran konformitas teman sebaya dan kenyamanan pelayanan terhadap perilaku konsumtif pada mahasiswa Fakultas Psikologi di Universitas Islam Sultan Agung Semarang. Terdapat tiga hipotesis yang diuji, hipotesis yang pertama adalah konformitas teman sebaya dengan perilaku konsumtif yang diperoleh nilai $\mathrm{R}$ sebesar 0,779 dan $\mathrm{F}$ sebesar 206,697, p 0,000 ( $<<0,01$ ). Sumbangan efektif pada konformitas teman sebaya dan kenyamanan pelayanan dengan perilaku konsumtif sebesar 60,8\%. Dapat diartikan bahwa konformitas teman sebaya dan kenyamanan pelayanan berkontribusi secara signifikan terhadap perilaku konsumtif pada mahasiswa Fakultas Psikologi di Universitas Islam Sultan Agung Semarang.

Mahrunnisya dkk., (2020) melakukan penelitian di 17 sekolah yang berbeda di Bandar Lampung pada siswa kelas XI IPS dan memperoleh hasil konformitas teman sebaya menyumbang $32,4 \%$ terhadap perilaku konsumtif. Hasil penelitian ini juga sesuai dengan hasil penelitian Kaushal dan Kumar, (2016) di mana konformitas teman sebaya atau pengaruh sosial merupakan hal utama yang dapat mempengaruhi pembelian produk karena adanya perubahan perilaku yang dipengaruhi oleh kelompok untuk mengikuti pedoman. Di sisi lain, kenyamanan pelayanan juga menjadi prediktor signifikan bagi perilaku konsumtif, di mana hal ini juga didukung oleh hasil penelitian yang menunjukkan bahwa mahasiswa yang berbelanja melalui mobile shopping kenyamanan pelayanan memiliki peran signifikan terhadap terjadinya perilaku konsumtif (Aridinta \& Widijoko, 2019). Adapun penelitian yang telah dilakukan oleh Mahkota dkk., (2014) menunjukkan bahwa ada 
hubungan yang signifikan antara kepercayaan, kenyamanan dengan keputusan pembelian, di mana variabel kenyamanan pelayanan termasuk dalam kategori tinggi jumlah 170 (81,2\%). Hasil penelitian ini sesuai dengan pernyataan Beauchamp dan Ponder, (2010) kenyamanan pelayanan merupakan kemudahan dan kecepatan konsumen untuk dapat memilih barang yang akan kosumen beli, desain dan tampian produk sehingga dapat mempengaruhi perilaku konsumtif seseorang untuk melalukan pembelian secara terus menerus.

Berdasarkan koefisen prediktor konformitas didapatkan 0,876, sementara kenyamanan pelayanan 0,325. Dari sini dapat dilihat bahwa kofnormitas menjadi prediktor yang lebih kuat dibandingkan kenyamanan pelayanan. Selain itu, dari hasil korelasi parsial, didapatkan nilai $r_{x 1 y}$ 0,716 untuk korelasi antara perilaku konsumtif dan konformitas, sementara didapatkan $r_{x l y} 0,252$ untuk kenyamanan pelayanan. Meski keduanya berada pada taraf signifikan, dapat dilihat bahwa koefisien korelasi konformitas lebih besar dibandingkan kenyamanan pelayanan. Penelitian yang dilakukan oleh Yang dan Polonsky (2012) menunjukkan bahwa hanya dua aspek dari kenyamanan pelayanan yaitu keuntungan dan keuntungan-pasca yang berhubungan dengan intensi perilaku, sementara kepuasan memediasi secara parsial kedua tipe kenyamanan tersebut. Ini juga diperkuat oleh hasil penelitian Kurniawan, Kartawan, Murni, \& Wihuda (2019) yang menunjukkan bahwa kenyamanan pelayanan memiliki dampak positif terhadap intensi perilaku konsumen. Lebih lanjut, hasil penelitian juga menunjukkan bahwa kenyamanan pelayanan menjadi penggerak motivasional bagi perilaku keterlibatan konsumen (consumer engagement behaior), di mana karakter organisasi secara signifikan mempengaruhi kenyamanan pelayanan yang mana pada akhirnya mempengaruhi perilaku keterlibatan konsumen (Roy dkk., 2020). Dari ketiga penelitian ini, dapat dilihat bahwa kenyamanan pelayanan berpengaruh secara parsial (maupun keseluruhan) terhadap intensi perilaku konsumen, bukan pada perilakunya secara langsung. Hal ini mungkin menjelaskan mengapa dalam perilaku konsumtif, konformitas lebih berpengaruh daripada kenyamanan pelayanan.

Kelemahan penelitian adalah pada terbatasnya sampel pada mahasiswa Fakultas Psikologi Unissula, sehingga daerah generalisasi pun terbatas. Penelitian yang akan datang disarankan dilakukan pada subjek selain mahasiswa dan populasi yang lebih luas. Selain itu, penelitian yang akan datang sebaiknya juga memeriksa variabel lain yang mungkin berpengaruh terhadap perilaku konsumtif seperti gaya hidup hedonis, kepuasan konsumen, dan lain sebagainya

\section{Conclusions}

Berdasarkan penelitian yang telah dilaksanakan oleh peneliti dapat disimpulkan bahwa terdapat hubungan yang signifikan antara konformitas teman sebaya dan kenyamanan pelayanan dengan perilaku konsumtif pada mahasiswa Fakultas Psikologi di Universitas Islam Sultan Agung Semarang. Lebih lanjut, juga diketahui bahwa ada hubungan positif yang signifikan antara konformitas teman sebaya dengan perilaku konsumtif berbelanja online melalui Shopee dan ada hubungan positif yang signifikan antara kenyamanan pelayanan dengan perilaku konsumtif berbelanja online melalui Shopee. Implikasi dari penelitian ini yakni dapat dilihat pentingnya konformitas dan kenyamanan pelayanan dari suatu e-commerce dalam perilaku konsumtif pada 
mahasiswa. Penelitian berikutnya dapat difokuskan pada variabel lain yang mungkin lebih mempengaruhi perilaku konsumtif seperti karakter konsumen yaitu gaya hidup, kontrol diri, dan kepuasan terhadap pelayanan.

\section{References}

Ancok, D. (1995). Nuansa psikologi pembangunan. Pustaka Pelajar.

Aridinta, Frinda Agnesya, \& Widijoko, G. (2019). Analisis pengaruh kenyamanan layanan online terhadap kepuasan konsumen mobile commerce. Jurnal Ekonomi Dan Bisnis.

Astutik, Y. (2021). Begini Perubahan Pola Belanja di Toko Online Selama Pandemi. Cnbcindonesia.Com. https://www.cnbcindonesia.com/tech/20210329124334-37233619/begini-perubahan-pola-belanja-di-toko-online-selama-pandemi

Azizah, P. N., \& Listiara, A. (2017). Hubungan antara konformitas dengan perilaku konsumtif dalam pembelian tas melalui online shop pada mahasiswi fakultas ilmu sosial dan ilmu politik (fisip) dan fakultas ilmu budaya (fib) universitas diponegoro. Empati: Jurnal Karya Ilmiah S1 Undip, 6(1), 332-337.

Beauchamp, M. B., \& Ponder, N. (2010). In-Store and Online Shoppers. Marketing Management Journal, 20(1), 49-65.

Berry, L. L., Seiders, K., \& Grewal, D. (2002). Understanding service convenience. Journal of Marketing, 66(3), 1-17. https://doi.org/10.1509/jmkg.66.3.1.18505

Burhan, F. A. (2021). Nilai transaksi e-commerce RI melonjak 91\%, Shopee kuasai pasar. In Katadata.co.id. https://katadata.co.id/yuliawati/digital/60ba67ba89507/nilai-transaksi-ecommerce-ri-melonjak-91-shopee-kuasai-pasar

Cahyanti, S. (2018). pengaruh overall convenience online shopping shopee terhadap behavioral intetion di surabaya. Jurnal Ilmiah Mahasiswa Universitas Surabaya, 7(2), 2993-3006.

Chang, Y.-W., \& Polonsky, M. J. (2012). The influence of multiple types of service convenience on behavioral intentions: The mediating role of consumer satisfaction in a Taiwanese leisure setting. International Journal of Hospitality Management, 31(1), 107-118. https://doi.org/https://doi.org/10.1016/j.ijhm.2011.05.003

Chiang, K. P., \& Dholakia, R. R. (2003). Factors driving consumer intention to shop online: An empirical investigation. Journal of Consumer Psychology, 13(1-2), 177-183. https://doi.org/10.1207/s15327663jcp13-1\&2_16

CNN Indonesia. (2021). Riset: Warga RI Juara Belanja Online Meski Internet Lambat. CNN Indonesia. https://www.cnnindonesia.com/teknologi/20210224134753-206-610348/riset-wargari-juara-belanja-online-meski-internet-lambat/1

Duarte, P., Costa e Silva, S., \& Ferreira, M. B. (2018). How convenient is it? Delivering online shopping convenience to enhance customer satisfaction and encourage e-WOM. Journal of Retailing and Consumer Services, 44 (May), 161-169. https://doi.org/10.1016/j.jretconser.2018.06.007

Dwi, H. J. (2020). Peta Persaingan E-Commerce Indonesia pada Kuartal II-2020. IPrice.

Fitriyani, N., Widodo, P. B., \& Fauziah, N. (2013). Hubungan antara konformitas dengan perilaku konsumtif pada mahasiswa di genuk indah semarang. Jurnal Psikologi Undip, 12(1), 1-14. https://doi.org/10.14710/jpu.12.1.1-14

Henry, H. (2019). Fitur interaktif jadi andalan shopee raih banyak pelanggan. Liputan6.Com. 
Idham, P. P., \& Mujiasih, M. E. (2017). Hubungan antara konformitas teman sebaya dengan perilaku konsumtif membeli pakaian pada mahasiswi angkatan 2016 fakultas psikologi universitas diponegoro. Empati, 6(4), 195-208.

Jiang, L. (Alice), Yang, Z., \& Jun, M. (2013). Measuring consumer perceptions of online shopping convenience. Journal of Service Management, 24(2), 191-214. https://doi.org/10.1108/09564231311323962

Kaura, V. (2013). Service Convenience, Customer Satisfaction, and Customer Loyalty: Study of Indian Commercial Banks. Journal of Global Marketing, 26(1), 18-27. https://doi.org/10.1080/08911762.2013.779405

Kaushal, S. K., \& Kumar, R. (2016). Factors Affecting the Purchase Intension of Smartphone: A Study of Young Consumers in the City of Lucknow. 8(12), 1-16.

Khafida, A. A., \& Nrh, F. (2020). Hubungan antara koformitas teman sebaya dengan perilaku konsumtif pembelian skincare di marketplace pada remaja putri SMA N 1 Kendal. Empati, 8(3), 106-110.

Kurniawan, A. A., Kartawan, Murni, S., \& Wihuda, F. (2019). Assessing the effects of service convenience on customer behavioral intention in low-cost hotel: The mediating role of customer satisfaction and perceived service value. International Journal of Scientific and Technology Research, 8(10), 2368-2378.

Mahkota, A. P., Suyadi, I., \& Riyadi. (2014). Pengaruh kepercayaan dan kenyamanan terhadap keputusan pembelian online (studi pada pelanggan website ride inc). Jurnal Administrasi Bisnis, 8(2), 1-7.

Mahrunnisya, D., Indriayu, M., \& Wardani, D. K. (2020). Pengaruh konformitas teman sebaya terhadap perilaku konsumtif pada siswa sma di kota bandar lampung. Jurnal Pendidikan Ekonomi , Ilmu Ekonomi, Dan Kewirausahaan, 2(1), 1-5.

Murtiadi, Danarjati, \& E. (2015). Psikologi Komunikasi. Psikosain.

Mustofa, M. A. N. (2019). Hubungan Antara Kontrol Diri dengan Perilaku Konsumtif Memodifikasi Motor Pada Anggota Club Motor Di Kota Semarang (Vol. 4, Issue 3).

Myers, D. G. (2012). Psikologi sosial edisi kesepuluh. Salemba Humanika.

Priwidianti, A. S. (2019). Hubungan antara Konformitas Teman Sebaya Dengan Perilaku Agresif Pada Siswa Di Smk Negeri 10 Semarang Skripsi (Vol. 4, Issue 3).

Roy, S. K., Shekhar, V., Quazi, A., \& Quaddus, M. (2020). Consumer engagement behaviors: do service convenience and organizational characteristics matter? Journal of Service Theory and Practice, 30(2), 195-232. https://doi.org/10.1108/JSTP-03-2018-0049

Sanjaya, L. J., Sawitri, D. R., Psikologi, F., \& Diponegoro, U. (2018). Hubungan antara Kenyamanan Pelayanan dengan Loyalitas Pelanggan: Studi pada Mahasiswa Universitas Diponegoro Pengguna Layanan Go-Jek Di Semarang. Empati, 6(4), 149-156.

Sears, O. D. (1991). Psikologi sosial. Penerbit Erlangga.

Septian, D. (2016). BPS: Jumlah E-Commerce di Indonesia Capai 26,2 Juta. Liputan6.Com.

Setiadi, N. J. (2013). Perilaku konsumen (edisi revisi. Kencana Perdana Media Grup.

Shopee. (2019). Raih Omzet Besar dengan Maksimalkan 5 Fitur Promosi Shopee! Inspiasi SHOPEE.

Sugianto, F. (2018). Indonesian online shopping behavior. 
Sumartono. (2002). Terperangkap dalam iklan: Meneropong imbas pesan iklan televisi. Alfabeta.

Uly, Y. A. (2021). Nilai Transaksi E-Commerce di RI diprediksi Tembus 330,7 Triliun pada 2021. In Kompas.com.

https://www.google.co.id/amp/s/amp.kompas.com/money/read/2021/08/16110522226

-nilai-transaksi-e-commerce-di-ri-diprediksi-tembus-rp-3307-triliun-pada-2021

Veritrans. (2012). E-commerce in indonesia. DailySosial.

Wahyudi. (2013). Tinjauan tentang perilaku konsumtif remaja pengunjung mall samarinda central plaza. EJournal Sosiologi, 1(4), 26-36. 
This page is intentionally left blank

Psikoislamika: Jurnal Psikologi dan Psikologi Islam 